\title{
Hydroacoustic observations of surface shoaling behaviour of young-of-the-year perch Perca fluviatilis (Linnaeus, 1758) with a towed upward-facing transducer
}

\author{
Wolfgang Nikolaus Probst*, Gregor Thomas, Reiner Eckmann \\ Limnological Institute, University of Konstanz, Mainaustrasse 252, 78457 Konstanz, Germany
}

\section{A R T I C L E I N F O}

Article history:

Received 23 May 2008

Received in revised form 2 October 2008

Accepted 20 October 2008

\section{Keywords:}

Echosounding

School

Depth distribution

Pelagic zone

Lake Constance

\begin{abstract}
A B S T R A C T
The near-surface distribution of young-of-the-year perch was observed with a towed upward beaming echosounder system (SIMRAD EK60 with a circular $7^{\circ}$ transducer). Perch aggregated densely in the epilimnion during daytime and dispersed evenly below the surface at night. Shoaling commenced in late June when perch metamorphosed from the larval to juvenile stage. Average shoal width was $6.6 \mathrm{~m}$ and average shoal height was $2.35 \mathrm{~m}$ in July, when perch were observed for the last time in the pelagic zone of Lake Constance.

Upward echosounding revealed the presence and near-surface distribution of pelagic juvenile perch and therefore this method can be used as a complementary survey tool to get more precise information about the distribution, behaviour and abundance of near-surface fish.
\end{abstract}

\section{Introduction}

Echosounding is one of the most feasible methods for in situ observation and documentation of fish distribution (Simmonds and MacLennan, 2005). Unfortunately, each echosounding application has its drawbacks: in vertical downward echosounding a blind zone of several meters below the surface has to be tolerated, as the transducer is mounted in a certain depth and cannot reliably measure objects within its near-field. Therefore objects within the first 2-3 m below the surface cannot be detected (Cech et al., 2005). Horizontal echosounding cannot determine the precise depth of an object, as the sound beam emitted by the transducer is bent by the vertical gradient in water temperature and reflected or scattered in an unpredictable manner at the thermocline and the surface. The only method for the detection of near-surface objects with precise depth information is thus vertical upward beaming, where the near-field of the transducer is not at the same depth as the investigated objects.

In larval and juvenile fish, behavioural adaptations have evolved to reduce the risk of mortality and optimize growth. Among these, shoaling is a common phenomenon among fish species experiencing high predation likelihood (Krause and Ruxton, 2002; Pavlov and

* Corresponding author. Tel.: +49 7531 883216; fax: +49 7531883533 E-mail address: wolfgang.probst@uni-konstanz.de (W.N. Probst).
Kasumyan, 2000). Shoaling decreases the risk for an individual to become a victim of a predator. The formation and synchronous swimming behaviour of schools distract the predator and reduce their capture efficiency. Shoaling is often species-, size- and even kin-assortive (Behrmann-Godel et al., 2006; Hoare et al., 2000; Krause, 1994). Besides reducing predation risk for the individual, shoaling can increase the foraging efficiency of planktivorous fish, when food resources are distributed in horizontal patches (Krause and Ruxton, 2002)

Perch larvae Perca fluviatilis (Linnaeus, 1758) hatch in the littoral zone in May and are transported into the open water within a few days after hatch (Urho, 1996). Wang and Appenzeller (1998) found perch in the open water of Lake Constance until the end of July, where they inhabited the epilimnion during day and night. During their pelagic stage they first feed on rotifers and small copepods and switch to large copepods and Daphnia with increasing gape size (Wang, 1994). While the abundance and distribution of pelagic perch has been investigated by Wang and Appenzeller (1998), the observation of their fine-scale depth distribution during day and night has not been attempted.

In the pelagic zone of Lake Constance, perch shoals are found directly below the surface during daytime and thus within the blind zone (mounting depth of transducer plus near-field) of a downward-beaming echosounder. In this study the shoaling behaviour of juvenile perch was observed by a towed upward beaming transducer as a method for the observation of near-surface objects. 


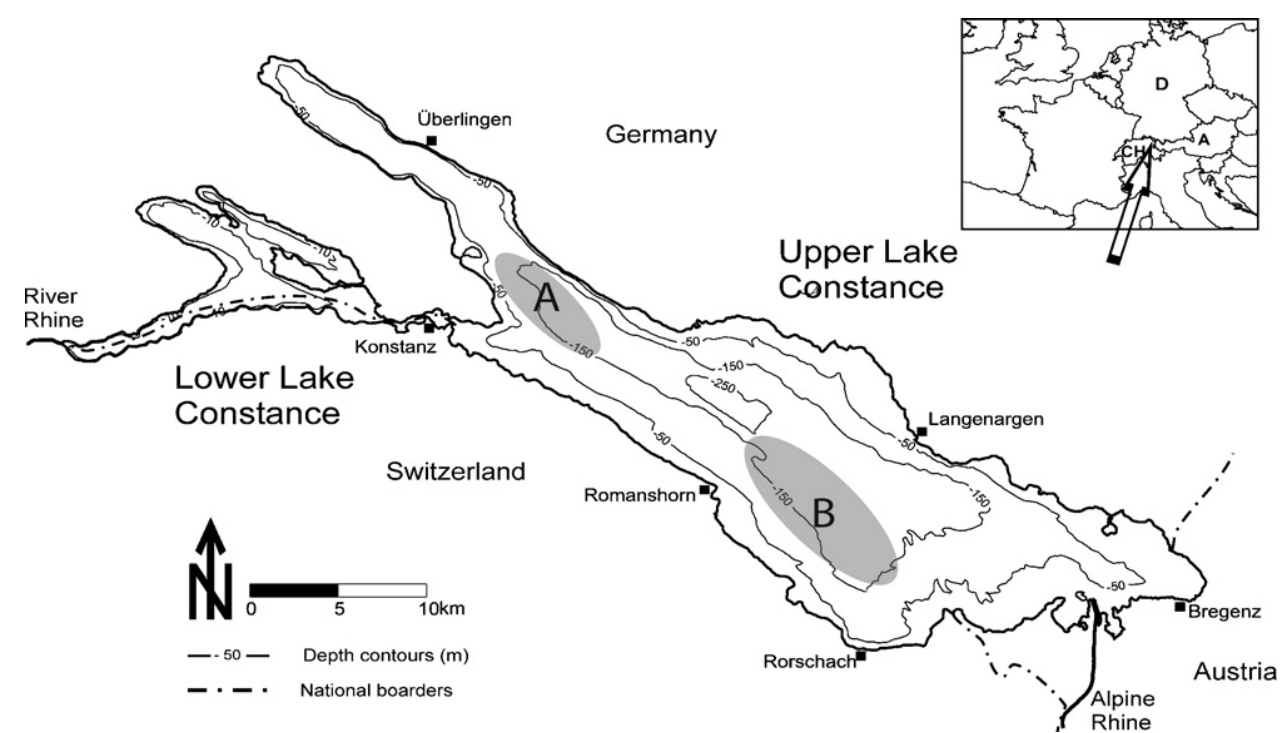

Fig. 1. Location of Lake Constance at the borders of Switzerland, Austria and Germany (small map, open arrow). The shaded areas indicate the areas of net catches and upward-beaming hydroacoustic surveys. Area A: net catches on the 30 May 2007, 29 June 2007 and hydroacoustic surveys on the 2 June 2007 and 24 June 2007 . Area B: hydroacoustic survey on the 7 July 2007.

\section{Materials and methods}

\subsection{Research area}

All data were sampled from the main basin of Upper Lake Constance, a warm monomictic pre-alpine lake with an average water depth of $101 \mathrm{~m}$ and a surface area of $456 \mathrm{~km}^{2}$ (Mürle et al., 2004). During the summer, the lake stratifies and a thermocline is established between 10 and $15 \mathrm{~m}$ depth. The echosounding surveys were conducted in the western part of Upper Lake Constance (2 June 2007 and 24 June 2007, Fig. 1, Area A) and in the south-eastern part of the main basin ( 7 July 2007, Area B). During the surveys the boat cruised on transects parallel to the main axis of the lake (NW-SE) within the research area (Fig. 1).

\subsection{Net catches}

From the middle of May until the beginning of August 2007 net catches were conducted in Area A (Fig. 1). Pelagic fish larvae/juveniles were caught with two conical ichthyoplankton nets at 0,5 and $10 \mathrm{~m}$ depth to confirm the presence of YOY perch. Unfortunately, catches were not performed quantitatively and thus abundance data from net catches were lacking. Instead, the minimum number of caught perch is indicated in Table 1.

The ichthyoplankton nets had a length of three meters, a circular opening of $1.4 \mathrm{~m}$ diameter and mesh sizes of $1200 / 800 \mu \mathrm{m}$ and $1600 / 1200 \mu \mathrm{m}$ in the front and rear, respectively. The net with $1200 / 800 \mu \mathrm{m}$ mesh size was used on the 30 May 2007, while the net with $1600 / 1200 \mu \mathrm{m}$ mesh size was used on the 29 June 2008

Table 1

No. of young-of-the-year (YOY) perch and burbot caught in the pelagic zone of Lake Constance. TL refers to the mean total length of all perch and burbot caught on the according day. Day refers to 6:00-21:00, dusk to 21:00-23:00, night to 23:00-4:30 and dawn to 4:30-6:00. Note that on the 30 May 2007 and 29 June 2007 the no. caught are not quantitative and hence do not indicate relative abundances of YOY perch and burbot! On the 29 June 2007 neither perch nor burbot were caught during daytime, because perch displayed strong gear avoidance and burbot migrated to the hypolimnion.

\begin{tabular}{|c|c|c|c|c|c|}
\hline Species & Date & Time & Catch depth (m) & No. caught & Mean TL $( \pm$ S.D. $)(\mathrm{cm})$ \\
\hline \multirow[t]{9}{*}{ Perch } & \multirow[t]{4}{*}{30 May 2007} & Day & 0 & 52 & \multirow{4}{*}{$1.26( \pm 0.21)$} \\
\hline & & Dusk & 0 & 42 & \\
\hline & & Night & 0 & 40 & \\
\hline & & Dawn & 0 & 30 & \\
\hline & \multirow[t]{4}{*}{29 June 2007} & Day & 0,3 & No catch & \multirow[t]{4}{*}{$2.14( \pm 0.63)$} \\
\hline & & Dusk & 0 & 24 & \\
\hline & & Night & 0 & 27 & \\
\hline & & Dawn & 0 & 24 & \\
\hline & 22 July 2007 & Dusk & 5 & 3 & $4.63( \pm 0.21)$ \\
\hline \multirow[t]{9}{*}{ Burbot } & \multirow[t]{4}{*}{30 May 2007} & Day & 28 & 12 & \multirow[t]{4}{*}{$0.87( \pm 0.17)$} \\
\hline & & Dusk & 20 & 29 & \\
\hline & & Night & 5 & 8 & \\
\hline & & Dawn & 0,28 & 17 & \\
\hline & \multirow[t]{4}{*}{29 June 2007} & Day & 25 & No catch & \multirow[t]{4}{*}{$1.36( \pm 0.21)$} \\
\hline & & Dusk & 20,0 & 14 & \\
\hline & & Night & 0 & 12 & \\
\hline & & Dawn & 0,28 & 9 & \\
\hline & 22 July 2007 & Dusk & 5 & 4 & $1.98( \pm 0.38)$ \\
\hline
\end{tabular}




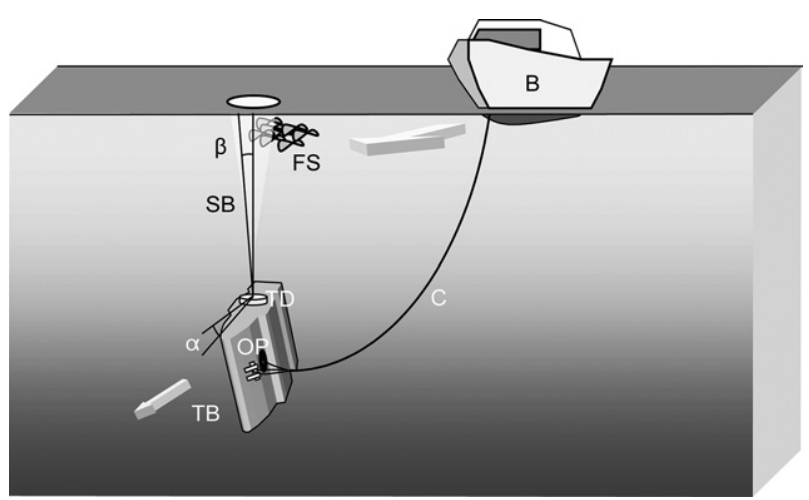

Fig. 2. Orientation of the tow-body for vertical upward beaming. $B=$ boat, $C=$ tow \& data cable, FS=fish shoal, $\mathrm{SB}=$ sound beam (shaded area), $\mathrm{TB}=$ tow-body, $\mathrm{TD}=$ transducer, $\mathrm{OP}=$ opening for cable $\alpha$ and $\beta$ are the pitch and roll angles of the transducer. Arrows indicate the direction of boat and the drag momentum on the tow-body.

and 22 July 2008. Depending on tow depth and weather conditions, the nets were trawled with a speed of $0.7-1.5 \mathrm{~m} \mathrm{~s}^{-1}$ for $5-15 \mathrm{~min}$. The speed was adjusted to maintain a constant depth, but was held as fast as possible. Caught fish were anesthetized and killed in trichloromethyl-propanol $\left(2 \mathrm{gl}^{-1}\right)$ directly after catch and subsequently put on ice. Within $6 \mathrm{~h}$, all fish were stored into a freezer at $-18^{\circ} \mathrm{C}$ until they were further processed. In the lab, the total length (TL) of frozen fish was measured to the nearest $0.1 \mathrm{~mm}$ under a dissecting microscope.

\subsection{Hydroacoustic surveys and data processing}

Surveys were conducted with a SIMRAD EK60 split-beam echo sounder equipped with an E120-7C transducer with $120 \mathrm{kHz}$ operating frequency and a nominal circular beam width of $7^{\circ}$. The EK60 was operated with a power output of $100 \mathrm{~W}$, a pulse length of $0.256 \mathrm{~ms}$ and $8.71 \mathrm{kHz}$ bandwidth. The ping interval ranged from 0.2 to $0.5 \mathrm{~s}$ per ping and was adjusted to avoid false bottom echoes. Data was stored on the hard drive of a laptop computer, which was also used to control the echosounder settings (PANASONIC Toughbook CF-27). A GPS system was attached to the computer and position data of the boat (WGS84) was logged. The system was calibrated in May 2007 with a $23 \mathrm{~mm}$ diameter copper sphere of $-40.4 \mathrm{~dB}$ target strength (TS) (at $1490 \mathrm{~m} \mathrm{~s}^{-1}$ sound speed) according to the manufacturer's manual.

The transducer was mounted into a hydrodynamic metal towbody, which was towed behind the boat by a $100 \mathrm{~m}$ connection cable (Fig. 2). The shape of the tow-body caused a hydrodynamic drag, pulling the tow-body to the starboard side and downwards. At a tow speed of $1.4 \mathrm{~m} \mathrm{~s}^{-1}$ the tow-body usually reached a depth of $18-21 \mathrm{~m}$. The deviation angles of the transducer's vertical beam axis from the horizontal $(\alpha)$ and vertical plain $(\beta)$ were measured with a pitch and roll sensor (sensor type: LIS3L02DQ, ST Microelectronics, Germany) during a pre-trial with an additional data cable (connecting the pitch and roll sensor and a laptop computer) attached to the tow-cable by straps. After the pre-trial the transducer was adjusted accordingly within the tow-body to achieve a beam axis perpendicular to the lake surface.
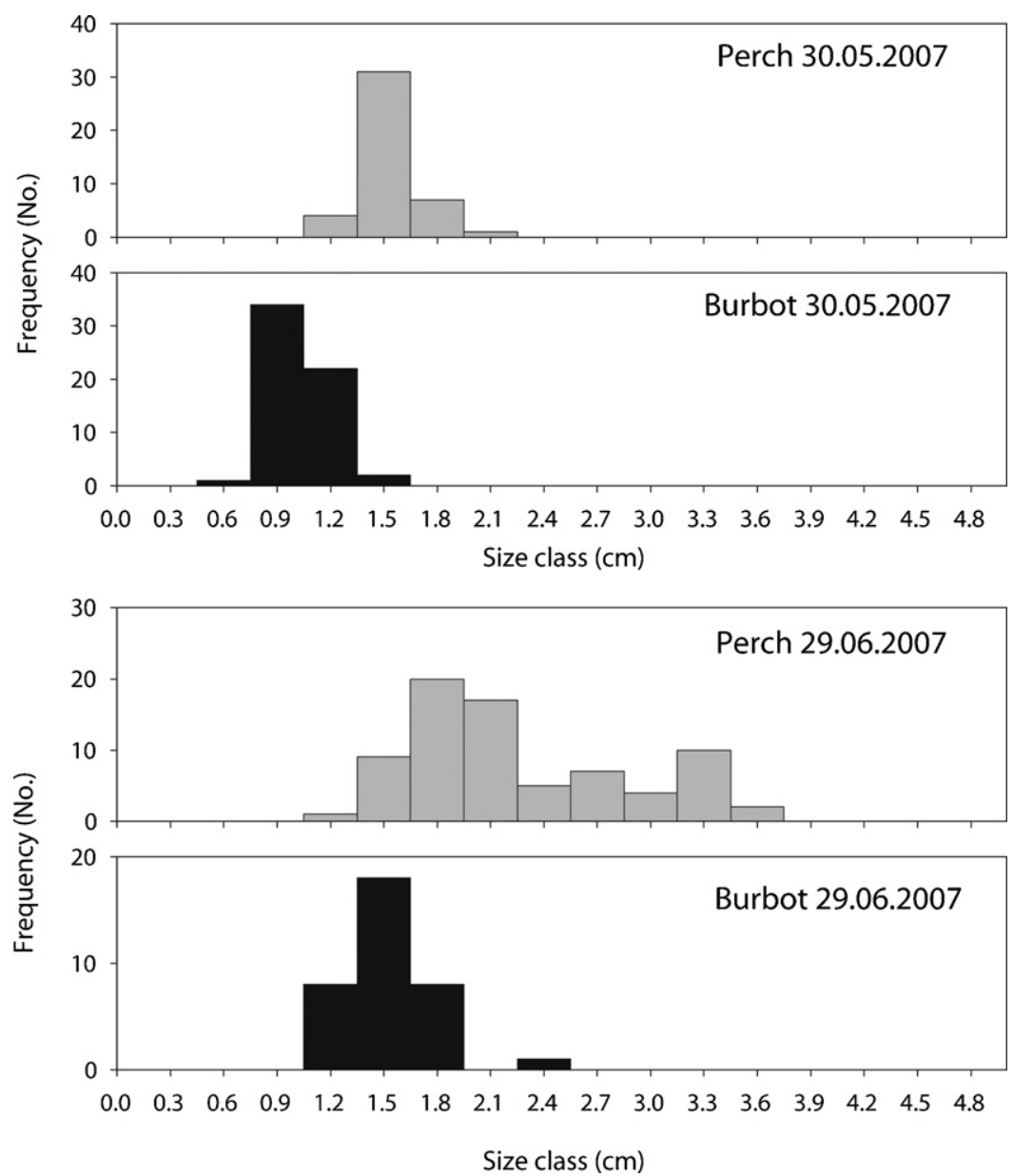

Fig. 3. Total length-frequency distribution of YOY perch and burbot on the 30 May 2007 and the 29 June 2007. X-axis labels indicate the upper limit of 3 mm size classes. 
Hydroacoustic data were analysed with SONAR5_Pro 5.9.6 (Balk and Lindem, 2006). The settings for single echo detection (SED) were a returned pulse width between 0.8 and 1.6 of the transmitted pulse length $(0.256 \mathrm{~ms})$ and a maximum one-way gain compensation of $3 \mathrm{~dB}$. Noise thresholds were set at $-75 \mathrm{~dB}$ in the $40 \log R$ (SED) and $-100 \mathrm{~dB}$ in the $20 \log R$ (amplitude) echograms for the 2 June 2007 and the 24 June 2007. On the 7 July 2007 SED noise threshold was set to $-70 \mathrm{~dB}$ to further reduce the influence of noise on abundance estimation. The surface was automatically detected with the bottom detection algorithm of SONAR5_Pro and adjusted manually, when the automatic detection did not provide an adequate fit.

The mean depth of perch was calculated as the volume densityweighted depth of $1 \mathrm{~m}$ thick sub-layers from the surface to $10 \mathrm{~m}$ depth. Shoal width and shoal height were measured within the echogram window of SONAR5_Pro and corrected according to Simmonds and MacLennan (2005).

\section{Results}

The catches in the pelagic epilimnion of Lake Constance consisted exclusively of YOY perch and burbot Lota lota (Linnaeus, 1758)
(Table 1$)$. Only very few perch juveniles $(N=3)$ were caught on the 22 July 2007, and hence the majority of YOY perch had left the pelagic zone before this date. The length-frequency (LF) distributions indicated that during the observation period burbot were usually smaller than perch (Fig. 3) and that the difference in the LFdistributions of perch and burbot increased from the 30 May 2007 to the 29 June 2007.

Contrary to the LF-distributions, the TS distributions of perch and burbot remained similar until the 24 June 2007 (Fig. 4). In spite of their smaller TL burbot seemed to have a larger TS than perch on the 2 June 2007. Three weeks later on the 24 June 2007, the TS-distributions of perch and burbot were similar while the TL of burbot was smaller than the TL of perch (see Fig. 3 on the 29 June 2008). On the 7 July 2007 the larger TL of perch in relation to burbot was also evident in the TS-distribution.

Upward echosounding revealed the shoaling of perch during daytime from the end of June (24 June 2007). No shoals could be detected on the 2 June 2007 (Fig. 4). The onset of shoaling coincided with the metamorphosis from larvae to juveniles. Shoal size increased from $4.9 \mathrm{~m}$ mean width and $2.35 \mathrm{~m}$ mean height in late June to $6.6 \mathrm{~m}$ mean width and 0.69 mean height in early July
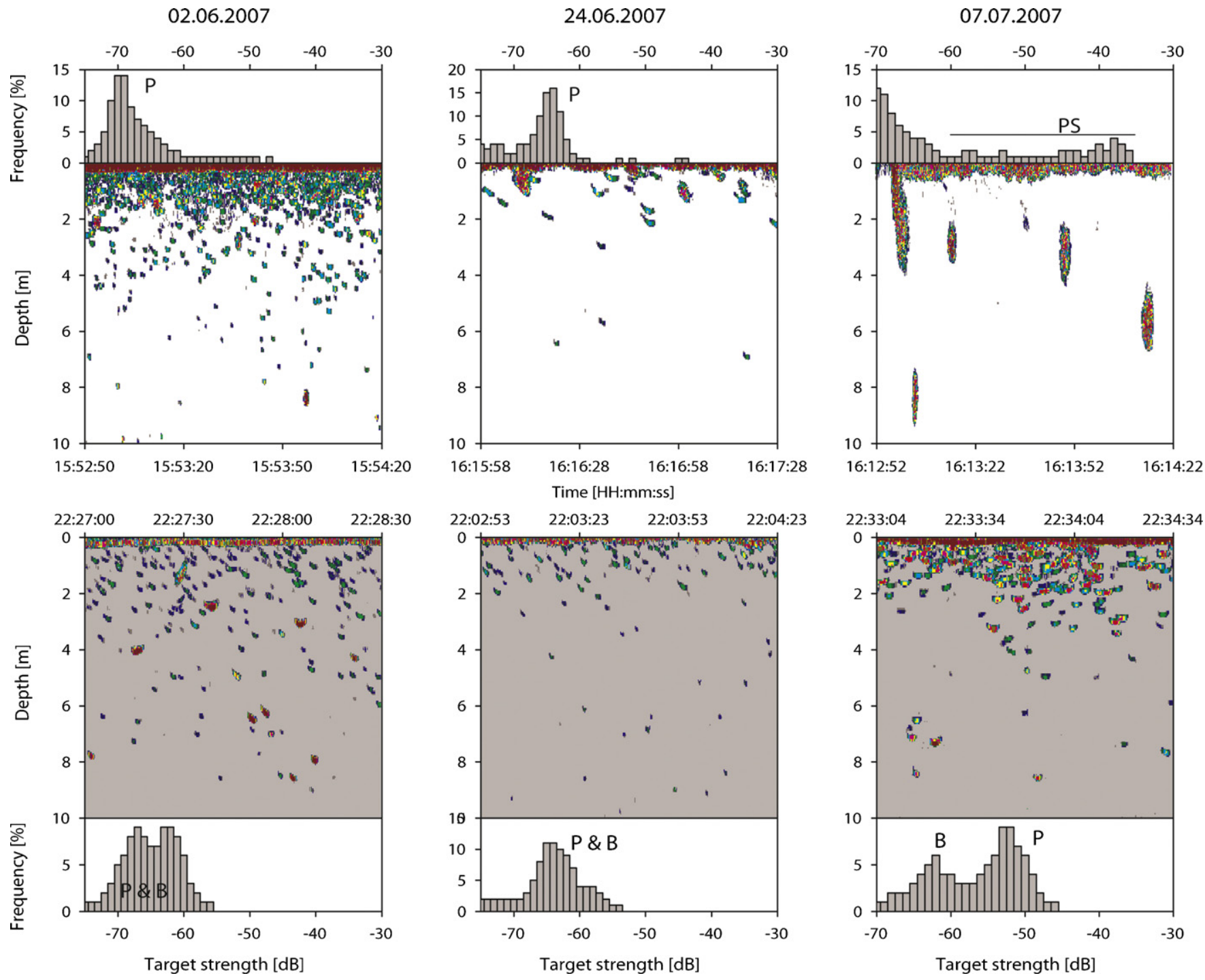

Fig. 4. Shoaling behaviour of juvenile perch and target strength (TS) on 2 June 2007 (left), 24 June 2007 (middle) and 7 July 2007 (right) at day (top) and night (bottom). Displayed are amplitude echograms $(20 \log R$ ) recorded by vertical upward echosounding during $90 \mathrm{~s}$. $\mathrm{P}=\mathrm{TS}$-peak attributable to YOY perch, $\mathrm{B}=\mathrm{TS}$-peak attributable to YOY burbot, PS = TS-peak attributable to perch in shoals. 
Table 2

Daytime depth range and average shoal dimensions ( \pm S.D.) of YOY perch in summer 2007 determined by vertical upward echosounding. Shoal dimensions were corrected to account for the pulse length and beam width (Simmonds and MacLennan, 2005). A total of 36 and 54 shoals were measured on the 24 June 2007 and the 7 July 2007 , respectively. Distance refers to the length of the analysed transect and no. pings is the number of pings contained within the transect.

\begin{tabular}{|c|c|c|c|c|c|c|c|}
\hline Date & Distance (m) & No. pings & Min. depth (m) & Mean depth (m) & Max. depth (m) & Mean width (m) & Mean height (m) \\
\hline 2 June 2007 & 3262 & 8050 & n.s. ${ }^{\mathrm{a}}$ & 1.28 & n.s. ${ }^{\mathrm{a}}$ & n.s. ${ }^{a}$ & n.s. ${ }^{a}$ \\
\hline 24 June 2007 & 2946 & 7994 & 0.00 & 3.16 & 9.33 & $4.9( \pm 1.77)$ & $0.69( \pm 0.50)$ \\
\hline 7 July 2007 & 3193 & 7999 & 0.00 & 3.55 & 10.93 & $6.6( \pm 3.50)$ & $2.35( \pm 1.33)$ \\
\hline
\end{tabular}

a n.s. $=$ no shoaling on the 2 June 2007.

(Table 2). During the day perch shoals were distributed between 0 and $10 \mathrm{~m}$ depth (Fig. 5). At night, perch dispersed below the surface. After nightfall $66 \%$ of the echo energy was observed in the first meter below the surface. Break-up of shoals occurred shortly after sunset (around 22:00 on the 7 July 2007, Fig. 6).

\section{Discussion}

The upward-beaming echosounder is a useful application to observe the behaviour of near-surface fish. Accordingly, the here presented system would also allow to estimate the abundance of YOY perch, which would be underestimated by a conventional downward-beaming hydroacoustic system. At day many shoals and at night $66 \%$ of the echo energy was right below the surface and would have been within the blind-zone of a downward-beaming transducer. Further, the tow-body may have the advantage of reducing adverse effects of shooing by the boat (Guillard et al., 2006). Hence abundance estimates of juvenile fish showing a distinct vessel avoidance reaction should be more reliable with a towed echosounder system. Unfortunately, the presented data does not allow a quantitative comparison of perch abundance estimates by downward- and upward-beaming and this objective has to be addressed in future research endeavors.

The upward-beaming system proved to be applicable in calm conditions (wind speed less than $2.8 \mathrm{~m} \mathrm{~s}^{-1}$ ) when the lake surface was smooth. However, wind-induced waves as well as waves from
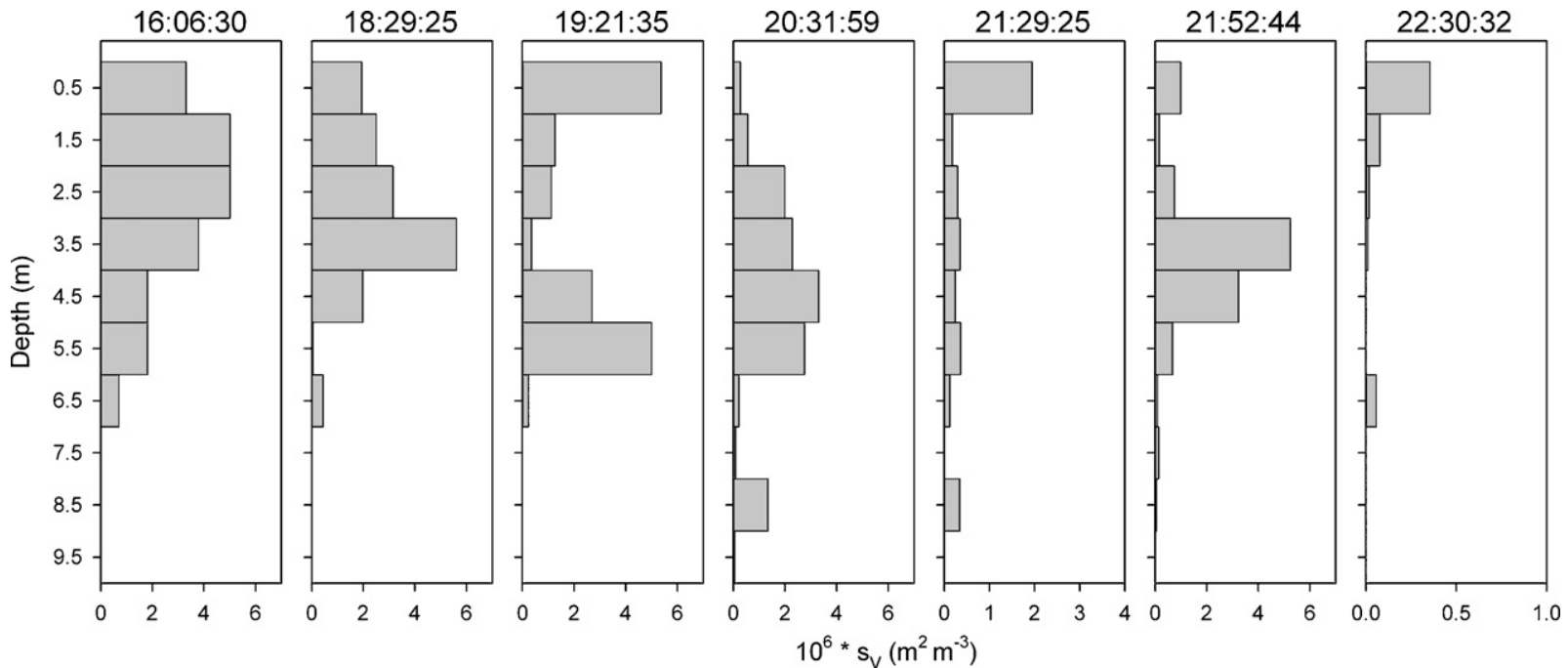

Fig. 5. Depth distribution of acoustic biomass $\left(s_{V}\right)$ on the 07 July 2008. $s_{V}$ was calculated at the indicated times (hh:mm:ss) for $1 \mathrm{~m}$ thick sub-layers from echogram sections containing 1000 pings, covering a period of at least $6 \mathrm{~min}$ and a distance of at least $395 \mathrm{~m}$ (depending on boat velocity).

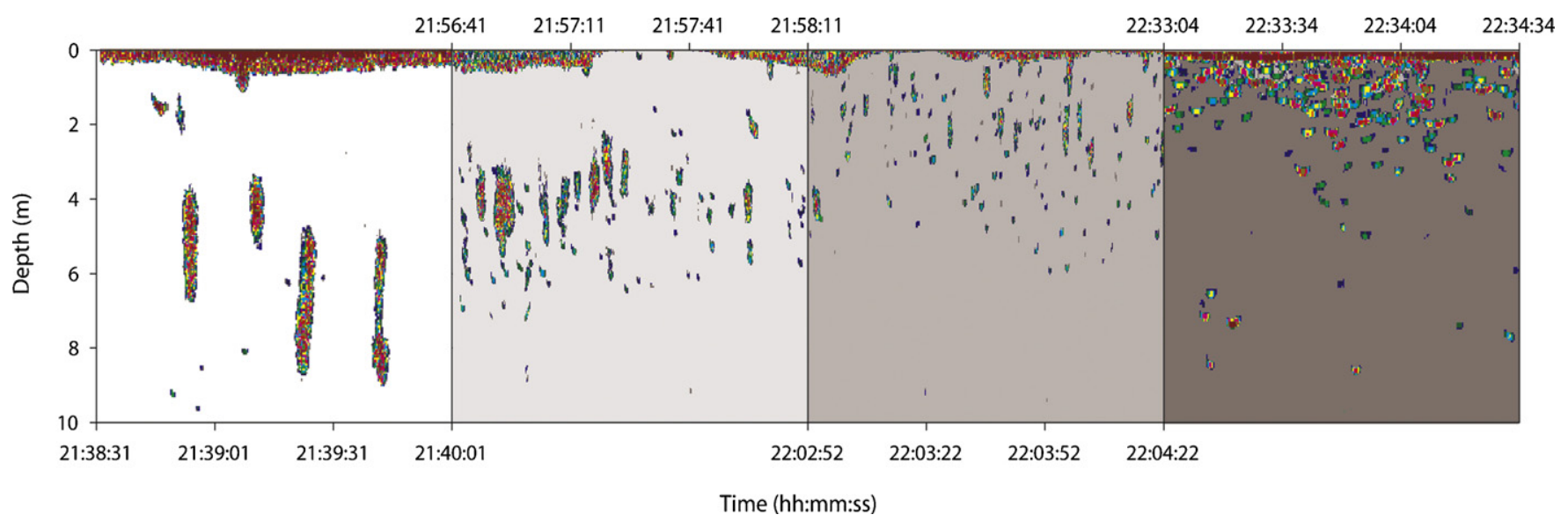

Fig. 6. Break-up of perch shoals on the 7 July 2007 between $21: 38$ and 22:34. The background colors in the amplitude echograms represent the declining light intensities during nightfall. 
commercial ferry boats resulted in a blurry surface line from which the fish could not be separated. Upward echosounding will therefore be most applicable in inland waters or sheltered marine areas with little wave disturbance at the surface.

Because the tow-body was towed by a $100 \mathrm{~m}$ long cable, it exerted considerable drag in the water. This resulted in a reduced maneuverability of the towing vessel. When turning the boat, wide curves of at least $250 \mathrm{~m}$ radius had to be made. The wide turning radius may limit the application of the presented system in small and narrow water bodies such as rivers or fjords. However, due to its limited size $(0.57 \mathrm{~m}$ height $\times 0.85 \mathrm{~m}$ length $\times 0.38 \mathrm{~cm}$ depth $)$ and weight (approximately $30 \mathrm{~kg}$ ) the tow-body can be deployed and retrieved by two persons. Thus in smaller lakes and narrow fjords the tow-body can be retrieved before turning the towing vessel.

Until the 24 June 2007 the TS-distributions were larger for burbot than for perch, whereas the LF-distributions indicated that perch usually had a larger TL than burbot. Hence YOY burbot seem to have better acoustic scattering properties than perch, which may be related to their swim bladder size. Because YOY burbot perform deep diel vertical migrations of $60 \mathrm{~m}$ amplitude (Miler and Fischer, 2004; Probst and Eckmann, 2008), their swim bladder may be fully inflated when coming to the surface after dusk.

During their larval ontogeny burbot perform diel vertical migrations with increasing amplitudes (Probst and Eckmann, 2008). Hence burbot were not present in the epilimnion during the day and the daytime echograms in Fig. 4 consisted mainly of perch.

The single echo detections within perch shoals during the day were larger than the single echo detections of dispersed perch at night suggesting an artefact due to acoustic scattering within the shoals (Simmonds and MacLennan, 2005). Fig. 4 clearly indicates that the large TS measured within the shoals at day do not derive from larger fish. After the break-up of shoals at dusk no targets larger than $-44 \mathrm{~dB}$ were present, which would be the expected TS size of adult lake whitefish Coregonus lavaretus (Linnaeus, 1758) (Eckmann, 1995). The mean TS of perch increased from $-66 \mathrm{~dB}$ on the 2 June 2007 to $-52 \mathrm{~dB}$ on the 7 July 2007 , which corresponds to 0.9 and $3.5 \mathrm{~cm}$ total length, respectively (Frouzova and Kubecka, 2004). These mean TS are in accordance with the observed TL of YOY perch (Table 1) and confirm their presence in the echograms of Fig. 4.

Shoaling behaviour of perch is most likely related to predator avoidance. Increased body size and metamorphosis may render perch more vulnerable to visual predators (Urho, 1996), aggravating the need for shoaling. Consequently, shoal size increased during the summer as indicated in Table 2. Predation on YOY perch by older age classes was observed in the middle of July 2006, when $1+$ perch caught in the pelagic zone of Lake Constance had up to six YOY perch in their stomach.

Perch stayed in the epilimnion of Lake Constance during the entire day, which has also been documented by Wang and Appenzeller (1998). A minor vertical displacement towards the surface was performed by perch, moving upward underneath the surface at night (Figs. 5 and 6). However, a distinct diel vertical migration below the thermocline as described by Cech et al. (2005) could not be observed. Instead, perch shoals were distributed randomly within the epilimnion, probably driven by the exploitation of patchily distributed zooplankton.

Pelagic shoaling of juvenile perch has been described in Lake Annecy, where large shoals could be detected from the beginning of June and remained in the pelagic zone until winter (Guillard et al., 2006). By contrast, YOY perch leave the pelagic zone of Lake Constance and migrate to the shallow littoral zone by late June or early July (Wang and Eckmann, 1994). The ontogenetic habitat shift of juvenile perch is commonly assumed to be induced by declining zooplankton abundance in summer (Wu and Culver, 1992), but its timing and extent may be influenced by lake size, lake trophic status and competition with other planktivorous fish (Persson and Greenberg, 1990).

\section{General conclusions}

The upward-beaming echosounding system presented in this study is a useful method to observe the distribution of near-surface fish. However, to obtain a good surface signal, which allows the separation of fish and surface signals, calm weather conditions and a smooth water surface are required.

Perch start to form shoals as they grow to approximately $2 \mathrm{~cm}$ total length. This size corresponds to the transition between the larval and juvenile stage and thus shoaling can be assumed to occur as a reaction to increased predation risk resulting from larger size and increased pigmentation.

\section{Acknowledgements}

This work was funded by the Deutsche Forschungsgemeinschaft (DFG) through the Collaborate Research Center CRC 454 "The littoral zone of Lake Constance". The plan for the tow-body was provided by Dr. Eckhard Bethke and Hans-Eberhard Götze from the Johann Heinrich von Thünen-Institut/Institute of Sea Fisheries, Hamburg. The tow-body was constructed by the workshop of the University of Konstanz. Joachim Böhler, Julia Mohs, John Hesselschwerdt and many others helped in the field.

\section{References}

Balk, H., Lindem, T., 2006. SONAR5_Pro. Oslo.

Behrmann-Godel, J. Gerlach, G.,Eckmann, R, 2006. Kin and population recognition in sympatric Lake Constance perch (Perca fluviatilis L.): can assortative shoaling drive population divergence? Behav. Ecol. Sociobiol. 59, 461-468.

Cech, M., Kratochvil, M., Kubecka, J., Drastik, V., Matena, J., 2005. Diel vertical migrations of bathypelagic perch fry. J. Fish Biol. 66, 685-702.

Eckmann, R., 1995. Abundance and horizontal distribution of Lake Constance pelagic whitefish (Coregonus lavaretus L.) during winter. Arch. Hydrobiol. Spec. Iss. Adv. Limnol. 46, 249-259.

Frouzova, J., Kubecka, J., 2004. Changes of acoustic target strength during juvenile perch development. Fish. Res. 66, 355-361.

Guillard, J., Perga, M.E., Colon, M., Angeli, N., 2006. Hydroacoustic assessment of young-of-year perch, Perca fluviatilis, population dynamics in an oligotrophic lake (Lake Annecy, France). Fish. Manage. Ecol. 13, 319-327.

Hoare, D.J., Krause, J., Peuhkuri, N., Godin, J.G.J., 2000. Body size and shoaling in fish. J. Fish Biol. 57, 1351-1366.

Krause, J., 1994. The influence of food, competition and predation risk on sizeassortive shoaling in juvenile chub (Leuciscus cephalus). Ethology 96, 105-116.

Krause, J., Ruxton, G.D., 2002. Living in Groups. Oxford University Press, Oxford.

Miler, O., Fischer, P., 2004. Distribution and onshore migration behaviour of burbot larvae in Lake Constance, Germany. J. Fish Biol. 64, 176-185.

Mürle, U., Ortlepp, J., Rey, P., 2004. Der Bodensee: Zustand-Fakten-Perspektiven. Internationale Gewässerschutzkommission für den Bodensee (IGKB). Bregenz (in German).

Pavlov, D.S., Kasumyan, A.O., 2000. Patterns and mechanisms of schooling behaviour in fish: a review. J. Ichthyol. 40, 163-231.

Persson, L., Greenberg, L.A., 1990. Optimal foraging and habitat shift in perch Perca fluviatilis in a resource gradient. Ecology $71,1699-1713$.

Probst, W.N., Eckmann, R., 2008. The influence of light on the diel vertical migration of young-of-the-year burbot Lota lota L. in Lake Constance. J. Fish. Biol. 73, 1-17.

Simmonds, J., MacLennan, D.N., 2005. Fisheries Acoustics-Theory and Practice. Blackwell Publishing, London.

Urho, L., 1996. Habitat shifts of perch larvae as survival strategy. Ann. Zool. Fenn. 33, 329-340.

Wang, N., Eckmann, R., 1994. Distribution of perch (Perca fluviatilis) during their first year of life in Lake Constance. Hydrobiologia 277, 135-143.

Wang, N., Appenzeller, A., 1998. Abundance, depth distribution, diet composition and growth of perch (Perca fluviatilis) and burbot (Lota lota) larvae and juveniles in the pelagic zone of Lake Constance. Ecol. Freshw. Fish. 7, 176-183.

Wu, L., Culver, D.A., 1992. Ontogenetic diet shift in Lake Erie age-0 yellow perch (Perca flavescens): a size-related response to zooplankton density. Can. J. Fish. Aquat. Sci. 49, 1932-1937. 